\title{
Inhibitory effect of naringenin on LPS- induced skin senescence by SIRT1 regulation in HDFs
}

\author{
Kye Hwa Lim ${ }^{1}$ and Gyu Ri Kim²
}

\begin{abstract}
Background: This study aims to investigate the ability of naringenin to regulate the expression of nuclear factor-kB, the upper gene of lipopolysaccharide-induced SIRT1; regulate signal transduction in the extracellular matrix, which plays an important role in the dermis; and alter the matrix metalloproteinase 1 and matrix metalloproteinase 3 gene expression, therefore having suppressing effect on skin cell senescence and deoxyribonucleic acid protection and cell protection effects and confirm naringenin's potential as an important cosmetic ingredient.

Methods: The efficacy of naringenin was assessed through reactive oxygen species assay, water-soluble tetrazolium salt assay, nuclear factor-kB luciferase assay, enzyme-linked immunosorbent assay, nicotinamide adenine dinucleotide phosphate oxidase activity assay, and quantitative real-time polymerase chain reaction.

Results: Sirt1, which regulates naringenin upstream of the nuclear factor-kB pathway, inhibits nuclear factor-kB activity and decreases matrix metalloproteinase expression level and SIRT1 gene dose-dependently. The results confirmed naringenin had an anti-aging effect on lipopolysaccharide-induced skin senescence. Various age-related biomarkers were used to analyze the inhibitory effect naringenin had on cell senescence progress and oxidative activity. Further experiments also showed naringenin also acted on NADPH oxidase, which produces superoxide (O2-), resulting in inhibiting NADPH oxidase activity. Experimental results reported that naringenin regulated the activity of SIRT1, which is the cause of modern skin cell aging, and in turn had a regenerative effect on reactive oxygen species-induced skin cellular senescence which affects skin elasticity and wrinkles.

Conclusions: This study confirmed that naringenin inhibits cellular senescence and regenerates human dermal fibroblasts damaged by lipopolysaccharide, and suggests that naringenin will be a cosmetic ingredient that has cell regenerative effects and anti-aging effects.
\end{abstract}

Keywords: Naringenin, Lipopolysaccharide, SIRT1, Human dermal fibroblasts, Nuclear factor-kB, Cellular aging, Skin cell regeneration, Antioxidation

\section{Background}

More than 300 theories have been proposed to explain the basic mechanisms for the progression of aging (Medvedev 1990). Among the three major theories, the first theory of reactive oxygen is a key mechanism of innate immunity (Harman 2006). The theory of free radicals was first introduced by Dr. Gerschman in 1954, but was developed by Dr. Denham Harman. In the free radical theory, it is

\footnotetext{
* Correspondence: grkim@eulji.ac.kr

${ }^{2}$ Department of Beauty and Cosmetic Science, Eulji University, 553,

Sanseong-daero, Sujeong-gu, Seongnam-si, Gyeonggi-do 13135, Republic of Korea

Full list of author information is available at the end of the article
}

known that reactive oxygen species (ROS), which are generated abnormally, can induce DNA damage and oxidation of proteins, nucleic acids, and lipids (Nakayama et al. 2016). Secondly, in the programmed cellular senescence theory (Aubert and Lansdorp 2008), the major mechanisms involved in the senescence process, which include the insulin/IGF-1 signaling pathway and the mTOR pathway as well as the AMP kinase (AMPK), and Sirtuin protein were found to be aging factors. Thirdly, according to the inflammation theory, immune responses decrease with aging, contributing to the increased

(c) The Author(s). 2018 Open Access This article is distributed under the terms of the Creative Commons Attribution 4.0 International License (http://creativecommons.org/licenses/by/4.0/), which permits unrestricted use, distribution, and reproduction in any medium, provided you give appropriate credit to the original author(s) and the source, provide a link to the Creative Commons license, and indicate if changes were made. The Creative Commons Public Domain Dedication waiver (http://creativecommons.org/publicdomain/zero/1.0/) applies to the data made available in this article, unless otherwise stated. 
incidence of different chronic diseases with an inflammatory component (Coppe et al. 2010).

With increased levels of the pro-inflammatory cytokines, interleukin (IL)-1 $\beta$, IL-6, and IL-8 are the senescence-associated secretory phenotype (SASP). While these theories aid the overall understanding of aging, the mechanism for skin disease and aging is difficult to define (Fagiolo et al. 1993).

Cells that are involved in skin wrinkles are fibroblasts, granulocytes, macrophages, and mast cells that are present in the dermis, which is a visible characteristic of skin aging that is of most importance to modern women. Decreased synthesis of collagen types I and III due to incomplete mechanical stimulation of the tissue forming the skin tissue and matrix metalloproteinase (MMP) activity forms skin sagging and deep wrinkles (Sardy 2009). Phenomenons caused by aging include changes in cell contact, insecure DNA replication at the end of chromosome, reduction of DNA repair ability, histone methylation modification, stem cell exhaustion, loss of quality of proteostasis ability of protein, mitochondrial dysfunction, nutritional control disorder, and increased senile senescence. As a typical phenomenon, cell senescence and telomere portions become shorter, and aging cells change the tissue microenvironment associated with matrix metalloproteinases, a kind of secretory phenotypes (Tchkonia et al. 2013), and induced matrix metalloproteinases, and in turn matrix metalloproteinases inhibit the synthesis of a generation of collagen in the body and thus represent an important feature of skin aging (Wondrak et al. 2003; Kimura et al. 2014).

Recent studies have shown that SIRT1 (silent mating type information regulation 2 homolog, Sirtuin 1), a SIR2 mutein that acts to enhance the viability of mammalian cells belonging to the longevity gene that regulates the activity of NF- $\mathrm{KB}$, is a nicotinamide adenine dinucleotide $(\mathrm{NAD}+)$ which is a class III deacetylase that is involved in a number of biological processes including DNA repair, energy metabolism, tumor suppression, and mitochondrial stabilization (Michan and Sinclair 2007). SIRT1-associated SIR2 is a type of sirtuin, a deacetylase that is dependent on nicotinamide adenine dinucleotide (NAD +), and these genes have been shown to have an effect on life prolongation in yeast and Drosophila (Cohen et al. 2004). Recent studies have also shown that SIRT1 plays a positive role in stress, metabolism, apoptosis, and premature aging. Environmental stresses such as smoking and air pollution are reported to reduce the production of SIRT1 in lungs, causing lung diseases (Rajendrasozhan et al. 2008). In addition, activation of NF-KB and activation of JNK, ERK, p38, and MAP kinase through SIRT1 expression inhibition lead to increased production of ROS. SIRT1 is mainly found in the nucleus and is known to deacetylate various proteins including p53, FOXO, NK-кB, Ku70, and histone (Haigis and Guarente 2006; Kimura et al. 2014).
SIRT1 plays an important role in cell survival by acting on cell cycle molecules and deacetylation of apoptosis regulatory proteins (Noh et al. 2013). As a factor controlling the development and differentiation of neurons, it has been recently reported to effectively inhibit neuronal dysfunction and nerve cell death in neurodegenerative diseases such as Alzheimer's disease and Parkinson's disease (Finkel and Holbrook 2000).

SIRT1 inhibits the secretion of inflammatory cytokines TNF- $\alpha$ and IL- 6 and increases the secretion of anti-inflammatory cytokine IL-10 (Lu et al. 2008) and has anti-inflammatory effects by downregulating the expression of various inflammatory cytokines in endothelial cells and macrophages (Michishita 2005; Stein and Matter 2011). As the expression level of SIRT1 decreases, the expression level of MMPs increases. Furthermore, by inhibiting the expression of MMP1, SIRT1 promotes the synthesis of extracellular matrix (Razaq et al. 2010).

SIRT1 and NF- $\mathrm{kB}$ system regulation, one of the most important causes of various common skin problems in modern people, represents an ancient signaling pathway that regulates metabolism and metabolism. This reaction inhibits the inflammatory cells of mammals through opposite regulation mechanisms (Salminen 2008; Kauppinena et al. 2013). Prevention of skin aging, anti-pollution, and inflammation treatments are primarily aimed at the cosmetic and medical industries; however, they are still insufficient (Rajendrasozhan et al. 2008).

Recently, reported anti-aging molecules have been developed to minimize intrinsic or extrinsic aging factors and to produce intracellular signaling molecules involved in collagen synthesis and its degradation (Rajendrasozhan et al. 2008; Mukherjee et al. 2011; Hwang et al. 2014). These antioxidants include antioxidants of natural raw materials through in vitro experiments, such as Ligularia fischeri, Rubus coreanus Miquel, Korean pine nut shells, lotus leaf, and bolus terminated chitosan, which is a seawood.

Through in vivo or human application tests, citrus, Oenanthe javanica, dandelion, soybean, Saururus chinensis, and Peucedanum japonicum Thunberg were proven as natural raw material antioxidants ( $\mathrm{Na}$ et al. 2016).

Naringenin (4',5,7-trihydroxy flavanone), a yellow crystalline powder, is hydrolyzed from a form of rutinoside of flavanone to an aglycone form. When the convert is complete, absorption is promoted and present at a higher concentration in plasma, bile, urine, etc., thus exhibiting anti-inflammatory effects in RAW 264.7 cell lines and anti-cancer effects in cancer cells (Fuhr and Kummert 1995; Tripoli et al. 2007).

Naringenin has a polyphenol structure capable of eliminating active oxygen groups and active oxygen generated by hydrogen/electron transfer in the 4-hydroxyl group of 
group B, and shows anti-inflammatory activity and antioxidant activity (Vafeiadou et al. 2009).

This study focused on the lack of research on naringenin's effects on skin, especially its potent as a cosmetic ingredient and its intracellular mechanism of action, and carried out experiments to investigate how naringenin regulates the activity of SIRT1, which in turn controls the activity of nuclear factor-кB, a major cause of modern skin aging, and has inhibitory effects on the reactive oxygen species production.

\section{Methods}

\section{Cell culture}

In this study, human dermal fibroblasts (HDFs) were purchased from Lonza Switzerland and cultured in Dulbecco's modified Eagle medium (DMEM; Hyclone, USA) supplemented with $10 \%$ fetal bovine serum (FBS; Hyclone), $1 \%$ penicillin/streptomycin (100 IU/mL penicillin, $100 \mu \mathrm{g} /$ $\mathrm{mL}$ streptomycin; Invitrogen, USA) and cultured at $37^{\circ}$ $\mathrm{C}$ and $5 \% \mathrm{CO}_{2}$.

\section{Sample treatment}

Naringenin (Sigma-Aldrich, USA) was used to dissolve the purified powder $(>99 \%)$ in a suitable concentration in dimethyl sulfoxide (DMSO; Sigma-Aldrich). Lipopolysaccharide (LPS), a cell-stimulating agent, was purchased from Sigma-Aldrich. For the experiment, the solution was dissolved in dimethyl sulfoxide (DMSO; Sigma-Aldrich) at a proper concentration. HDFs $\left(1 \times 10^{6}\right.$ cells/well $)$ were incubated in a $60-\mathrm{mm}$ cell culture dish for $24 \mathrm{~h}$. An appropriate concentration of naringenin was added to the culture medium. Lipopolysaccharide was co-treated at a constant concentration for $24 \mathrm{~h}$ and analyzed $3 \mathrm{~h}$ later. The significance of PCR was validated using a melting curve. The gene expressions were compared for analysis by normalizing the $\beta$-actin expression.

\section{Cell viability estimation}

WST-1 Cell Proliferation Assay System used a chromogenic material, formazan, which is formed from tetrazolium salts (WST-1) by intracellular mitochondrial dehydrogenase, to quantify cell proliferation and cell viability. Human dermal fibroblasts were inoculated into metabolically active 96-well plates, at a concentration of $3 \times 10^{3}$ cells/well, and cultured for $24 \mathrm{~h}$. HDFs were simultaneously treated with various samples such as naringenin and LPS and cultured for $24 \mathrm{~h}$. Ten microliters of EZ-Cytox cell viability assay kit reagent (ItsBio, Korea) was added to the cultured cells and incubated for $1 \mathrm{~h}$. The absorbance was measured at $490 \mathrm{~nm}$ using a microplate reader (Bio-Rad, USA). The mean and standard deviation of cell viability were calculated after repeating the procedure three times.

\section{qRT-PCR analysis}

Changes of gene expression caused by naringenin in the cells were quantitatively confirmed. qRT-PCR was performed by mixing $0.2 \mu \mathrm{M}$ primers, $50 \mathrm{mM} \mathrm{KCl}, 20 \mathrm{mM}$ Tris/ $\mathrm{HCl} \mathrm{pH}$ 8.4, $0.8 \mathrm{mM}$ dNTP, $0.5 \mathrm{U}$ Extaq DNA polymerase, $3 \mathrm{mM} \mathrm{MgCl} \mathrm{2,} \mathrm{and} \mathrm{1X} \mathrm{SYBR} \mathrm{green} \mathrm{(Invitrogen).}$ PCR was validated by melting curve. The melting curve confirmed the validity of PCR. Expression of each gene was standardized and compared. The primers used in this experiment are shown in Table 1.

\section{ROS assay}

To investigate the effect of naringenin on the removal of reactive oxygen species, ROS scavenging assay was performed. Human dermal fibroblasts were seeded in a $60-\mathrm{mm}$ culture dish at $2 \times 10^{5}$ cells/well and cultured for $24 \mathrm{~h}$. Cells were treated appropriately, cultured for an additional $24 \mathrm{~h}$, added $10 \mu \mathrm{M}$ of dichlorofluorescein diacetate (DCF-DA), and then cultured for $30 \mathrm{~min}$. After cells were harvested and analyzed for changes in ROS using a flow cytometer (BD Biosciences, USA). N-Acetyl-L-cysteine (NAC; Calbiochem, USA) serving as a ROS scavenger was also measured in the same manner.

\section{Nuclear factor-KB luciferase assay}

To investigate the effect of naringenin on the nuclear factor- $\mathrm{\kappa} B$ transcriptional activity, the nuclear factor- $\mathrm{K} B$ promoter luciferase assay was used. In this experiment, the nuclear factor-кB reporter NIH-3T3 stable cell line (Panomics, USA) containing the reporter gene with the nuclear factor- $\mathrm{KB}$ promoter consensus sequence was used in the promoter region. Nuclear factor- $\mathrm{KB}$ reporter $\mathrm{NIH}-3 \mathrm{~T} 3$ stable cells were inoculated in a $60-\mathrm{mm}$ culture dish at a concentration of $2 \times 10^{5}$ cells, cultured for $24 \mathrm{~h}$, treated with appropriate conditions, and cultured for additional $24 \mathrm{~h}$. The cultured cells were harvested; passive lysis buffer (Promega, USA) was added, put in ice for $10 \mathrm{~min}$, dissolved, then centrifuged at $12,000 \mathrm{rpm}$ at $4{ }^{\circ} \mathrm{C}$ for $30 \mathrm{~min}$ to recover the supernatant. A sample containing the same amount of protein was added to a black 96-well plate ( $80 \mu \mathrm{g}$ each), followed by luciferin (Promega, USA). The luminescence of luciferin was measured using a luminometer (Veritas, USA).

\begin{tabular}{lll}
\multicolumn{2}{l}{ Table $\mathbf{1}$ Lists of primers } \\
\hline Gene & Forward primer & Reverse primer \\
\hline B-actin & GGATTCCTATGTGGGCGACGA & CGCTCGGTGAGGATCTTCATG \\
SIRT1 & GCAGGTTGCGGGAATCCAA & GGCAAGATGCTGTTGCAAA \\
MMP1 & TCTGACGTGATCCCAGAG & CAGGGTGACACCAGTGACT \\
& AGCAG & GCAC \\
MMP3 & ATTCCATGGAGCCAGGCTTC & CATTGGGTCAAACTCCAA \\
& CTGTG \\
HO-1 & GCCTGCTAGCCTGGTTCAAG & AGCGGTGTCTGGGATGAACTA \\
\hline
\end{tabular}


Enzyme-linked immunosorbent assay (ELISA)

MMPs (Merck, USA; sandwich) and PGE2 (Cayman chemical, USA; competitive) were evaluated using an enzyme-linked immunosorbent assay (ELISA) kit according to the instruction manual for the HDF culture medium. Prostaglandin E2, MMPs, and monoclonal antibody were immobilized on plastic cell culture dish wells. One hundred microliters of each culture medium was dispensed (at room temperature for $2 \mathrm{~h}$ ). After washing five times each with a single washing buffer, $100 \mu \mathrm{L}$ horseradish peroxidase (HRP)-conjugated anti-MMP1 antibody was added for $1 \mathrm{~h}$ at room temperature, and $100 \mu \mathrm{L}$ of tetramethylbenzidine (TMB) was added and incubated for $30 \mathrm{~min}$ in a dark room. The absorbance was measured at 405-420 nm (PGE2) and $450 \mathrm{~nm}$ (MMPs).

\section{Nicotinamide adenine dinucleotide phosphate oxidase assay}

Naringenin has an antioxidative effect on the oxidase activity of reduced NADP, NADPH, which directly influences superoxide anion (O2-) production, which in turn plays the most fundamental role in ROS production. To study the antioxidative effect of naringenin on NADPH oxidase activity, using HDFs, $100 \mu \mathrm{L}$ of homogenates was added to each well and $900 \mu \mathrm{L}$ of $50 \mathrm{mM}$ phosphate buffer (1 mM EGTA, $150 \mathrm{mM}$ sucrose, $5 \mathrm{mM}$ lucigenin, 100 mM NADPH, pH 7.0) was added which was examined through lucigenin chemiluminescence assay.

\section{Statistical process}

All experiments were performed independently three times, and the results were expressed as mean \pm standard deviation. Student's $t$ test was used to analyze all findings, with a $p$ value of $0.05,0.01$, or 0.001 below considered as statistically significant $\left({ }^{*} p<0.05,{ }^{* *} p<0.01\right.$, $\left.{ }^{* * * *} p<0.001\right)$.

\section{Results}

Cytotoxicity of naringenin and lipopolysaccharide

Lipopolysaccharide acts as an endotoxin in cells, activating signals such as MAPK, NF-кB, and IRF-3 and promoting excessive secretion of inflammatory cytokines ( $\mathrm{Lu}$ et al. 2008). Lipopolysaccharide induced nuclear factor-KB activity through I $\mathrm{KB}$ phosphorylation and its degradation. In this study, WST-1 assay was performed to determine the cytotoxicity of naringenin in human dermal fibroblasts. Human dermal fibroblasts were treated with untreated control group and naringenin-treated group at 1-, 2-, 5-, and 10- $\mathrm{MM}$ dose levels, each respectively, for $24 \mathrm{~h}$.

Cell viability of untreated control group was set as $100 \%$, and up to $1-\mu \mathrm{M}$ dose level, the survival rate was shown to be $100 \%$ or more. When naringenin was treated at $1-, 2-$, $5-$, and $10-\mu \mathrm{M}$ dose levels, the cell viability levels of $101 \%$, $107 \%, 117 \%$, and $110 \%$ did not decrease, confirming almost no toxicity (Fig. 1a). To confirm the changes in the survival rate of cells, HDFs was treated with LPS at 1-, 2-, 3-, 4-, and $5-\mu \mathrm{g}$ dose levels, respectively, and the survival rate was $94 \%$ at $1 \mu \mathrm{g} / \mathrm{mL}$ (Fig. $1 \mathrm{~b}$ ).

\section{Protective effect of naringenin on LPS-induced cell senescence in HDFs \\ Changes in Sirt1 expression}

SIRT1 inhibits NF- $\mathrm{kB}$, a protein complex that promotes inflammatory responses. Furthermore, by inhibiting the MMP1 production, SIRT1 promotes the synthesis of extracellular matrix (Wang et al. 2012).

qRT-PCR was performed to study the SIRT1 expression. Compared to the control group, SIRT1 expression was decreased to 0.56 level at $1-\mu \mathrm{g}$ dose of LPS. However, when naringenin treatment was applied, SIRT1 gene expression increased back in a dose-dependent manner, resulting in 0.64 level at $5 \mu \mathrm{M}$ and 0.86 level at $10 \mu \mathrm{M}$ (Fig. 2a).
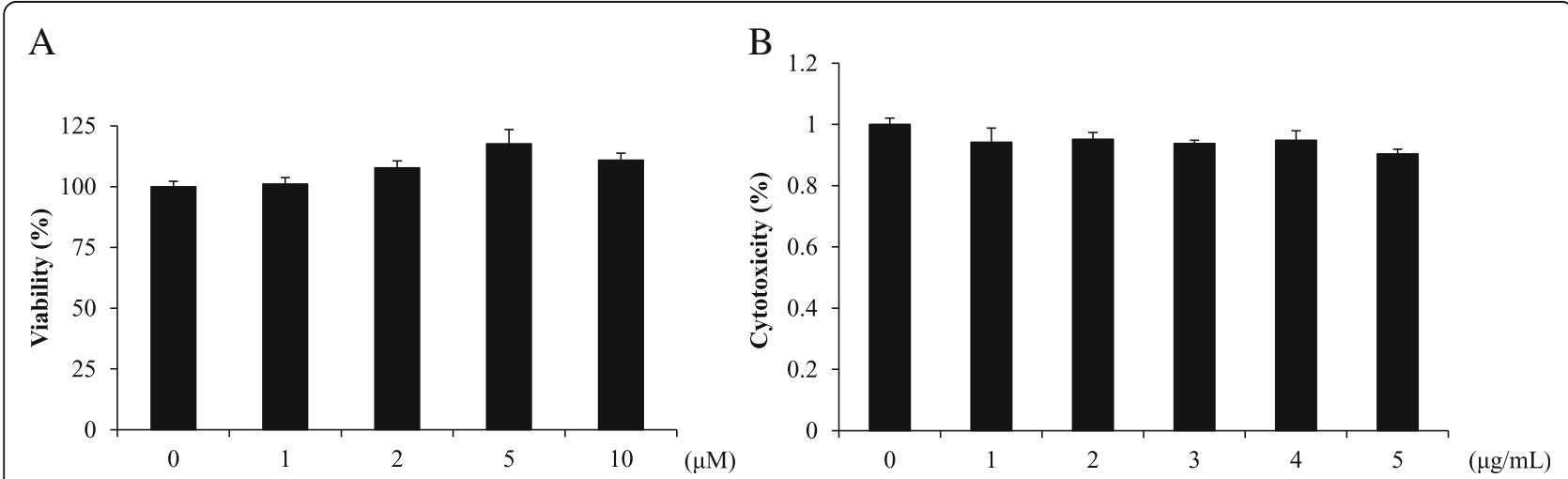

Fig. 1 Cytotoxicity of naringenin and lipopolysaccharide. a The cellular toxicity of LPS in HDFs. No statistically significant cytotoxicity was observed in the groups treated with naringenin nontreated control group and naringenin. $\mathbf{b}$ The cellular toxicity of naringenin in HDFs 


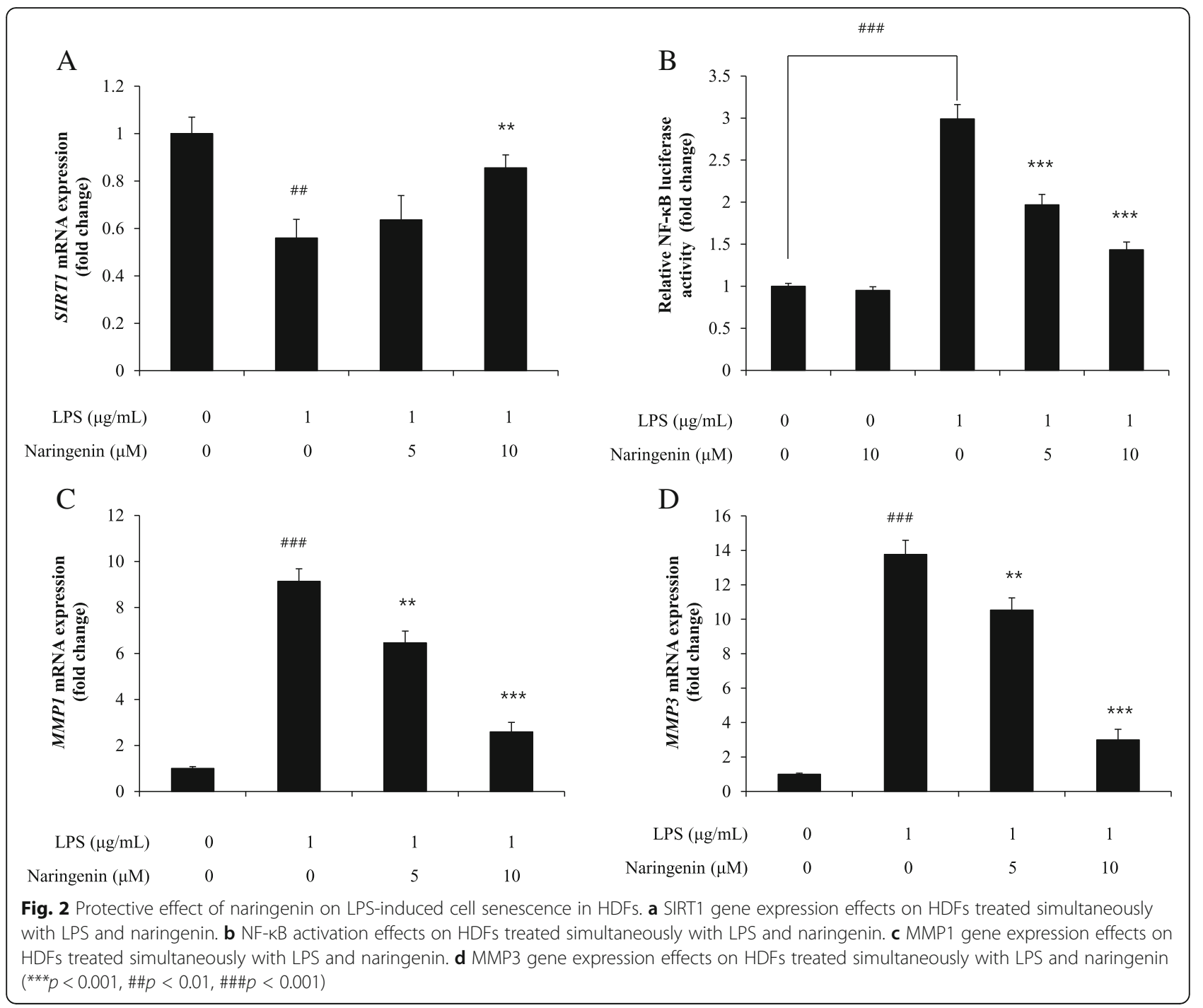

\section{Changes in nuclear factor- $k B$ expression}

In NF- $\kappa B$ signaling pathway, NF- $\kappa B$ is activated by LPS through phosphorylation and is then translocated to the nucleus, promoting the transcription of inflammatory cytokines and mediators, initiating various diseases (Lvashkiv 2011; Schett et al. 2013).

When LPS was treated with NF-kB luciferase assay, cell expression level increased to 3.0. When naringenin was treated with 5- and 10- $\mu \mathrm{M}$ dose levels, cell expression level each decreased to 2 and 1.4. Therefore, cell interval level was dose-dependently reduced by naringenin (Fig. 2b).

\section{Changes in MMP1 and MMP3 expression}

ELISA was performed to determine the effect of naringenin on the dermis by assaying the antigen or antibody using antigen-antibody reaction after binding the enzyme to the antibody, in order to investigate the effect of naringenin on the dermal structure of the skin through the changes of MMPs, an anti-aging index, and to examine the changes in gene expression of MMP1 and MMP3, which break down type I collagen of dermis related to skin wrinkles.

When HDFs were not treated with naringenin and LPS, the level of MMP1 gene expression was 1.0, and when treated by LPS, the level increased to 9.1. However, the level of MMP1 gene expression was decreased by naringenin in a dose-dependent manner to 6.4 at $5 \mu \mathrm{M}$ treatment and 2.5 at $10 \mu \mathrm{M}$ treatment (Fig. 2c). In addition, when HDFs were not treated with naringenin and LPS, MMP3 gene expression level was 1.0 and when treated with LPS, MMP3 gene expression level increased to 14. However, MMP3 expression decreased in a dose-dependent manner with naringenin, with MMP3 gene expression level decreasing from 11 to 3 when pretreatment of $5 \mu \mathrm{M}$ and $10 \mu \mathrm{M}$ were each applied (Fig. 2d). Therefore, naringenin was shown to inhibit MMP1 and MMP3 gene expression in the dermis. 
Protective effect of naringenin on oxidative stress by LPS in HDFs

\section{Expression changes in ROS production}

ROS activates NF- $\mathrm{kB}$, a transcriptional factor of inflammatory response through LPS stimulation, and in turn activates pro-inflammatory factors such as cytokines, NO, PGE2, iNOS, COX2, IL-1ß, MCP-1, MIP-1, IL-16, IL-18, and M-CSF, which contributes to the development of chronic diseases (Levi et al. 1998; Knott et al. 2000; Rivest 2003).

To investigate the effect of naringenin on the total intracellular amount of ROS in LPS-treated HDFs, fluorescent probe DCF-DA was performed. When naringenin and NAC treatment were not present, LPS treatment increased the total amount of ROS level to 2.1. At $5 \mu \mathrm{M}$ dose, naringenin decreased the level to 1.7 and further decreased the level to 1.2 at $10 \mu \mathrm{M}$. When the control group NAC was treated with $10 \mathrm{mM}$, the total amount of ROS level decreased to 1.0.
The results showed that at a low concentration of $10 \mu \mathrm{M}$, naringenin reduced ROS in a dose-dependent manner compared to the $10 \mathrm{mM}$ of NAC applied on the positive control group, showing inhibiting effects on normal skin cell function impairment which resulted in excellent antioxidant activity (Fig. 3a).

\section{Changes in NADPH oxidase expression}

NADPH oxidase exists in vascular smooth muscle cells and endothelial cells and is also a major source of peroxidation that causes vascular disease and atherosclerosis. NADPH oxidase is a multiple enzyme complex consisting of large gp91phox known as Nox2, a small protein p22phox, and three cytosolic components p40phox, p47phox, p67phox, and Rac (Zalba et al. 2005). Cellular stimulation directly produces superoxide (O2-) and is produced by the activity of NADPH oxidase.

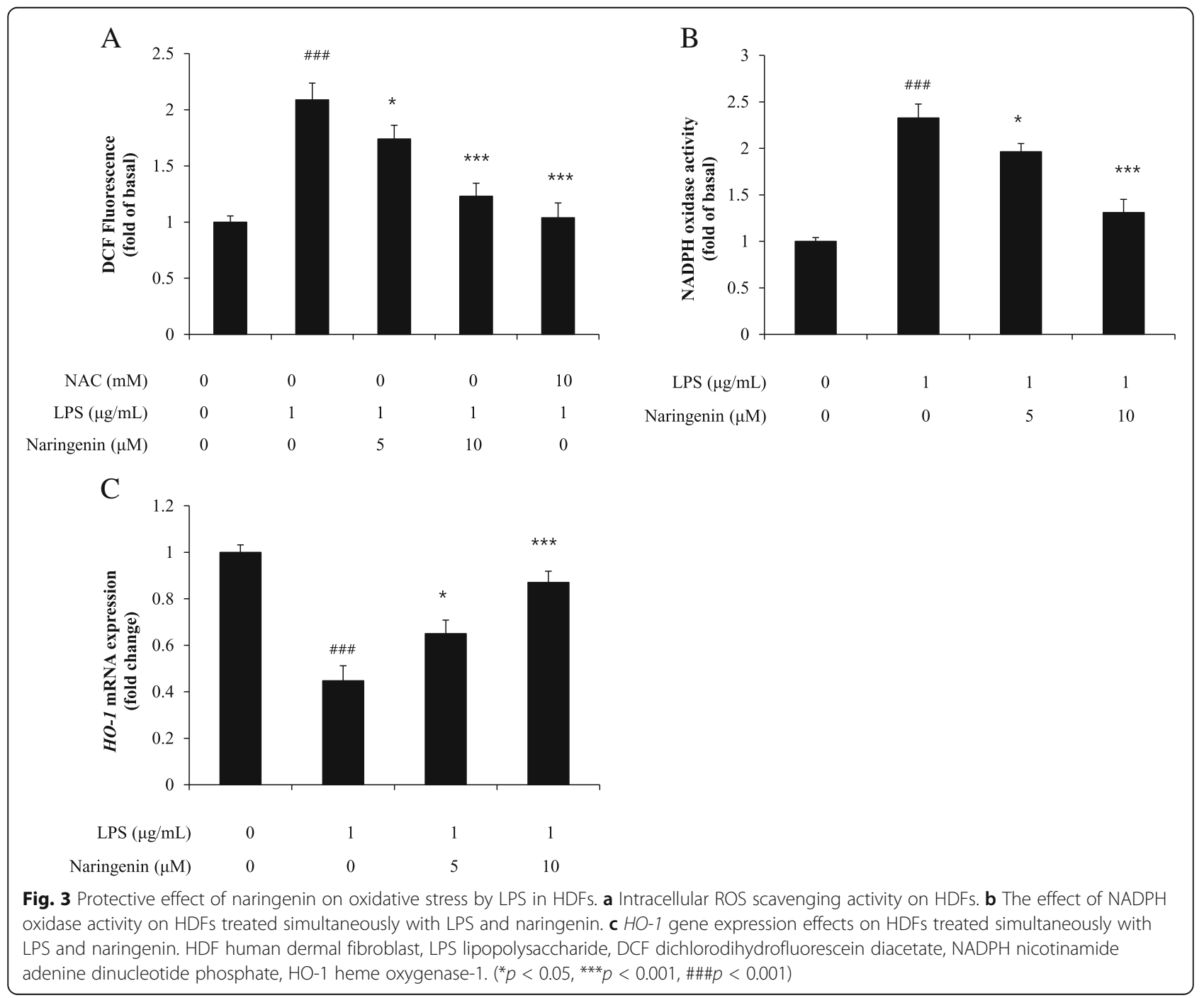


When LPS was treated with naringenin, cell interval level increased to 2.3. When naringenin was treated with 5 and $10 \mu \mathrm{M}$ concentrations, the cell interval levels decreased to 2.0 and 1.3. Therefore, naringenin was shown to have dose-dependent reducing effect (Fig. 3b).

\section{Changes in HO-1 expression}

Heme oxygenase-1 (HO-1), one of the representative protective enzymes in the human body, shows protective effects through strong anti-apoptosis and antioxidant action during hepatic ischemia and reperfusion $(40,41)$.

To study the effect naringenin has on the dermal structure, the changes in HO- 1 expression was analyzed through qRT-PCR assay. When LPS was treated with naringenin, the cell interval level increased to 0.4 . When naringenin was treated at 5 and $10 \mu \mathrm{M}$ concentrations, the level increased to 0.7 and 0.9 . Therefore, it was confirmed that naringenin increased $\mathrm{HO}-1$ expression again in a dose-dependent manner (Fig. 3c).

\section{Discussion}

Inhibitory effect of naringenin on aging HDFs in SIRT1

Aging cells release several factors called SASPs, which have deleterious effects on surrounding cells as well as tissues. Molecular activation of the inflammation-inducing gene by the redox signal pathway ultimately leads to inflamed tissues and organs, or aging (Cheng et al. 2011; Hall et al. 2003). We found that an increase in NF- $\mathrm{kB}$ activation and expression of inflammatory molecules, in addition to an increase in oxidative stress, causes exogenous aging and photoaging. We also found that endogenous aging occurs due to a combination of various internal factors over time and is mainly represented by cellular senescence. The main cause of cellular senescence is oxidative stress, which stops cell division and growth by blocking the cell cycle. MMP1, which is widely distributed in human tissues, is secreted by fibroblasts and mainly degrades type II collagen, a major component of cartilage matrix, as well as types VII and VI collagen (Roberts et al. 2006; Donmez 2012). In addition, when MMP1 cleaves the middle portion of collagen fibers, MMP3 and MMP9 subdivide and cleave the collagen further. HDFs regulate collagen metabolism through interaction of MMP1, tissue inhibitor of metalloproteinase 1 (TIMP1), type I collagen, transforming growth factor beta 1 (TGF- $\beta 1$ ), and various cytokines. SIRT1, a major anti-senescence agent that inhibits the activity of these MMPs, is activated through nuclear histones, transcription factors, and protein deacetylation of cell-signaling mediators, which causes cell signaling, anti-aging, gene expression of cell protection, and neuronal differentiation (Wang et al. 2012; Correia et al. 2017). Recently, SIRT1 activation has been reported to suppress endoplasmic reticulum stress in renal tubular cells. In addition, resveratrol, polyphenol, and
SIRT1 activators mimic the anti-aging effects of calorie restriction in lower organisms, mitigate insulin resistance, and increase mitochondrial content in rats with a high-fat diet, resulting in their prolonged survival. SIRT1 also inhibits NF- $\mathrm{kB}$, a protein complex that promotes inflammatory responses. Furthermore, by inhibiting MMP1 expression, SIRT1 promotes ECM synthesis (Wang et al. 2012). The degree of skin wrinkles and thickened skin formed by ROS controls MMP activity, which is highly correlated with aging features such as skin sagging and may lead to tumors due to their imbalance. It has been reported that ROS inhibits the transcriptional activity of Smad by inhibiting TGF- $\beta$, a growth-promoting factor, and so inhibits the expression of downstream collagen genes (Quan et al. 2010; Otterbein et al. 2003).

Using quantitative real-time polymerase chain reaction (qRT-PCR) assay and enzyme-linked immunosorbent assay (ELISA), we examined how naringenin affects the expression of the NF-kB upstream gene, SIRT1, and the downstream genes, $M M P 1$ and MMP3. The results showed that naringenin increases the expression of SIRT1 and decreases the expression of MMP1 and MMP3 in a dose-dependent manner.

In conclusion, naringenin regulates the expression of $N F-\kappa B$; regulates signal transduction in the ECM, which has important functions in the dermis; and alters SIRT1, $M M P 1$, and $M M P 3$ expression. Therefore, naringenin has a suppressing effect on skin cell senescence, DNA protection, and cell protection, indicating that it can be an important cosmetic ingredient.

\section{Inhibition of oxidation by naringenin through inhibition of ROS activity}

$\mathrm{NADPH}$ oxidase directly influences the production of the superoxide anion $\left(\mathrm{O}^{2-}\right)$, which plays the most fundamental role in ROS production, and the inducible form of nitric oxide synthase (iNOS), which is related to the immune response in NOS and produces $\mathrm{NO}$, which is important for immune cell signaling. $\mathrm{ONOO}^{-}$, a potent oxidant that forms naturally in cells by the reaction of $\mathrm{NO}$ and $\mathrm{O}^{2-}$, induces apoptosis and inflammation.

$\mathrm{O}^{2-}$ is an oxygen molecule produced in cells. It is then converted to $\mathrm{H}_{2} \mathrm{O}_{2}$ through a spontaneous reaction or enzymatic catalysis. In addition, when a transition metal $(\mathrm{Fe}, \mathrm{Cu})$ is present, Fenton's reaction reduces $\mathrm{O}^{2-}$ to $\mathrm{H}_{2} \mathrm{O}_{2}$ which are eliminated by the antioxidative enzymes superoxide dismutase (SOD) and catalase. However, the body lacks controlling enzymes for $\mathrm{OH}^{-}$, which is harmful and is known to the human body (Chen and Ames 1994). Heme oxygenase-1 (HO-1) removes cause stains, wrinkles, and freckles through oxidation of inflammatory, toxic-free heme $\left(\mathrm{Fe}^{2+}\right)$, treats damaged cells, and protects the body from oxidative stress by increasing bilirubin, a bile pigment that removes ROS. HO-1 is also a cell-protecting 
enzyme that produces biliverdin and iron and is a potent antioxidant that protects the body against various oxidative stress-related diseases. HO-1 can also inhibit endoplasmic reticulum stress ( $\mathrm{Hu}$ et al. 2015).

In conclusion, naringenin inhibits NADPH oxidase activity, which produces $\mathrm{O}^{2-}$, removes $\mathrm{ROS}$, and increases HO-1 gene expression. The results of this study suggested that naringenin inhibits the damaging and aging effects of toxic substances that cause aging and skin inflammation.

\section{Conclusions}

Naringenin is a flavanone known to have physiological antioxidant and active oxygen-scavenging properties. It has a polyphenol structure capable of eliminating active oxygen groups and active oxygen generated by hydrogen/ electron transfer in the 4-hydroxyl group of group B and has anti-inflammatory effects and antioxidant properties (Lee et al. 2016; Hee et al. 2018). SIRT1 inhibits NF-кB, a protein complex that promotes inflammatory responses and is correlated with common skin diseases caused by harmful particulate matter (PM) and environmental pollutants. Furthermore, by inhibiting the expression of MMP1, SIRT1 promotes ECM synthesis.

This study analyzed the anti-aging and antioxidative effects of naringenin by observing changes in the expression of the longevity gene SIRT1 and the downstream genes MMP1 and MMP3 in the cell senescence model of LPS-induced HDFs. The results showed that naringenin increases SIRT1 expression and decreases NF- $\kappa B, M M P 1$, and $M M P 3$ expression in a dose-dependent manner. Additional experiments confirmed the ability of NADPH oxidase to inhibit $\mathrm{O}^{2-}$ activity, remove $\mathrm{ROS}$, and increase HO-1 gene expression.

In conclusion, this in vitro research confirmed that naringenin not only increases SIRT1 activity but, by blocking the NF- $\kappa B$ pathway, also inhibits the gene expression of inflammatory factors (which are major components of SASPs) and substances that produce ROS. Naringenin can be used as an effective cosmetic ingredient to prevent age-induced skin elasticity reduction and wrinkled skin, troublesome skin diseases, and premature skin aging caused by harmful environmental pollutants, PM, etc.

\section{Acknowledgements}

Not applicable.

\section{Funding}

Not applicable.

Availability of data and materials

Not applicable.

\section{Authors' contributions}

KHL and GRK did all of the research background such as experiments, data collecting, and statistical analysis as well as drafting the manuscript. Both authors read and approved the final manuscript.
Ethics approval and consent to participate

Not applicable.

\section{Consent for publication}

Not applicable.

\section{Competing interests}

The authors declare that they have no competing interests.

\section{Publisher's Note}

Springer Nature remains neutral with regard to jurisdictional claims in published maps and institutional affiliations.

\section{Author details}

${ }^{1}$ Department of Beauty Care, Sangji Youngseo College, 84, Sangjidae-gil, Wonju-si, Gangwon-do 26339, Republic of Korea. ${ }^{2}$ Department of Beauty and Cosmetic Science, Eulji University, 553, Sanseong-daero, Sujeong-gu,

Seongnam-si, Gyeonggi-do 13135, Republic of Korea.

Received: 25 October 2017 Accepted: 22 August 2018

Published online: 01 November 2018

\section{References}

Aubert G, Lansdorp PM. Telomeres and aging. Physiol Rev. 2008;88:557-79.

Chen $\mathrm{Q}$, Ames BN. Senescence-like growth arrest induced by hydrogen peroxide in human diploid fibroblast F65 cells. Proc Natl Acad Sci. 1994:91:4130-4.

Cheng J, Phong B, Wilson DC, Hirsch R, Kane LP. Akt fine-tunes NF-kappaBdependent gene expression during T cell activation. J Biol Chem. 2011; 286:36076-85

Cohen HY, Miller C, Bitterman KJ, Wall NR, Hekking B, Kessler B, Howitz KT, Gorospe M, de Cabo R, Sinclair DA. Calorie restriction promotes mammalian cell survival by inducing the SIRT1 deacetylase. Science. 2004;305:390-2.

Coppe JP, Desprez PY, Krtolica A, Campisi J. The senescence-associated secretory phenotype: the dark side of tumor suppression. Annu Rev Pathol. 2010;5:99-118.

Correia M, Perestrelo T, Rodrigues AS, Ribeiro MF, Pereira SL, Sousa MI, RamalhoSantos J. Sirtuins in metabolism, stemness and differentiation. Biochim Biophys Acta. 2017;1861:3444-55.

Donmez G. The neurobiology of sirtuins and their role in neurodegeneration. Trends Pharmacol Sci. 2012;33:494-501.

Fagiolo U, Cossarizza A, Scala E. Increased cytokine production in mononuclear cells of healthy elderly people. Eur J Immunol. 1993;23:2375-8.

Finkel T, Holbrook NJ. Oxidants, oxidative stress and the biology of ageing. Nature. 2000:408:239-47.

Fuhr U, Kummert AL. The fate of naringin in humans: a key to grapefruit juicedrug interactions? Clin Pharmacol Ther. 1995:58:365-73.

Haigis MC, Guarente LP. Mammalian sirtuins-emerging roles in physiology, aging and calorie restriction. Genes Dev. 2006:0:2913-21.

Hall MC, Young DA, Waters JG, Rowan AD, Chantry A, Edwards DR. The comparative role of activator protein 1 and Smad factors in the regulation of Timp-1 and MMP-1 gene expression by transforming growth factor-beta 1. J Biol Chem. 2003;278:10304-13.

Harman D. Free radical theory of aging: an update: increasing the functional life span. Ann N Y Acad Sci. 2006;1067:10-21.

Hee JY, Kim GR, Ahn JJ, An IS, Kim YS. Inhibition of apoptosis and antiinflammatory effects of embelin. Asian J Beauty Cosmetol. 2018;16: 103-12.

Hu Y, Duan M, Liang S, Wang Y, Feng Y. Senkyunolide I protects rat brain against focal cerebral ischemia-reperfusion injury by up-regulating p-Erk1/2, Nrf2/HO1 and inhibiting caspase 3. Brain Res. 2015;1605:39-48.

Hwang E, Park SY, Lee HJ, Lee TY, Sun ZW, Yi TH. Gallic acid regulates skin photoaging in UVB-exposed fibroblast and hairless mice. Phytother Res. 2014 28:1778-88.

Kauppinena A, Suuronen T, Ojalab J, Kaarniranta K, Salminen A. Antagonistic crosstalk between NF-KB and SIRT1 in the regulation of inflammation and metabolic disorders. Cell Signal. 2013;25(10):1939-48.

Kimura Y, Sumiyoshi M, Kobayashi T. Whey peptides prevent chronic ultraviolet B radiation-induced skin aging in melanin-possessing male hairless mice. J Nutr. 2014;144:27-32.

Knott C, Shern G, Wilkin GP. Inflammatory regulators in Parkinson's disease: iNOS, lipocortin-1, and cyclooxygenase-1 and -2. Mol Cell Neurosci. 2000;16:724-39. 
Lee SJ, Han HS, An IS, Ahn KJ. Effects of amentoflavone on anti-inflammation and cytoprotection. Asian J Beauty Cosmetol. 2016;14:201-11.

Levi G, Minghetti L, Aloisi F. Regulation of prostanoid synthesis in microglial cells and effects of prostaglandin E2 on microglial functions. Biochimie. 1998;80:899-904.

Lu YC, Yeh WC, Ohashi PS. LPS/TLR4 signal transduction pathway. Cytokine. 2008:42:145-51.

Lvashkiv LB. Inflammatory signaling in macrophages: transitions from acute to tolerant and alternative activation states. Eur J Immunol. 2011;41:2477-81.

Medvedev ZA. An attempt at a rational classification of theories of aging. Biol Rev. 1990;65:375-98.

Michan S, Sinclair D. Sirtuins in mammals: insights into their biological function. Biochem J. 2007:404:1-13.

Michishita E. Evolutionarily conserved and nonconserved cellular localizations and functions of human SIRT proteins. Mol Biol Cell. 2005;16(10):4623-35.

Mukherjee T, Kim WS, Mandal L, Banerjee U. Interaction between Notch and Hifalpha in development and survival of Drosophila blood cells. Science. 2011; 332:1210-3.

$\mathrm{Na}$ EJ, Jang HH, Kim GR. Review of recent studies and research analysis for antioxidant and anti-aging materials. Asian J Beauty Cosmetol. 2016;14(4):481-91.

Nakayama H, Nishida K, Otsu K. Macromolecular degradation systems and cardiovascular aging. Circ Res. 2016;1 18:1577-92.

Noh SJ, Kang MJ, Kim KM. Acetylation status of P53 and the expression of DBC1, SIRT1, and androgen receptor are associated with survival in clear cell renal cell carcinoma patients. Pathology. 2013;45:574-80.

Otterbein LE, Soares MP, Yamashita K, Bach FH. Heme oxygenase-1: unleashing the protective properties of heme. Trends Immunol. 2003;24(8):449-55.

Quan T, Shao Y, He T, Voorhees JJ, Fisher GJ. Reduced expression of connective tissue growth factor (CTGF/CCN2) mediates collagen loss in chronologically aged human skin. J Invest Dermatol. 2010;130:415-24.

Rajendrasozhan S, Yang SR, Kinnula VL, Rahman I. SIRT1, an antiinflammatory and antiaging protein, is decreased in lungs of patients with chronic obstructive pulmonary disease. Am J Respir Crit Care Med. 2008;177(8):861-70.

Razaq S, Wilkins RJ, Urban JP. The effect of extracellular pH on matrix turn over by cells of the bovine nucleus pulposus. Eur Spine J. 2010;12:341-9.

Rivest S. Molecular insights on the cerebral innate immune system. Brain Behav Immun. 2003;17:13-9.

Roberts S, Evans H, Trivedi J, Menage J. Histology and pathology of the human intervertebral disc. J Bone Joint Surg Am. 2006;88:10-4.

Salminen A. Interaction of aging-associated signaling cascades: inhibition of NFkappaB signaling by longevity factors FoxOs and SIRT1. Cell Mol Life Sci. 2008;65(7-8):1049-58.

Sardy M. Role of matrix metalloproteinases in skin ageing. Connect Tissue Res. 2009:50:132-8.

Schett G, Elewaut D, Mclnnes IB, Dayer J, Neurath MF. How cytokine networks fuel inflammation: toward a cytokine-based disease taxonomy. Nat Med. 2013;19:822-4

Stein S, Matter CM. Protective roles of SIRT1 in atherosclerosis. Cell Cycle. 2011;10:640-7.

Tchkonia T, Zhu Y, van Deursen J, Campisi J, Kirkland JL. Cellular senescence and the senescent secretory phenotype: therapeutic opportunities. J Clin Invest. 2013;123:966-72.

Tripoli E, Guardia ML, Giammanco S, Majo DD, Giammanco M. Citrus flavonoids: molecular structure, biological activity and nutritional properties. Food Chem. 2007;104:466-79.

Vafeiadou K, Vauzour D, Lee HY, Rodriguez-Mateos A, Williams RJ, Spencer JPE. The citrus flavanone naringenin inhibits inflammatory signalling in glial cells and protects against neuroinflammatory injury. Arch Biochem Biophys. 2009; 484(1):100-9.

Wang DW, Hu ZM, J Hao. SIRT1 inhibits apoptosis of degenerative human disc nucleus pulposus cells through activation of Akt pathway. AGE. 2013;35: $1741-53$.

Wondrak GT, Roberts MJ, Cervantes-Laurean D, Jacobson MK, Jacobson EL. Proteins of the extracellular matrix are sensitizers of photo-oxidative stress in human skin cells. J Invest Dermatol. 2003;121:578-86.

Zalba G, San José G, Moreno MU, Fortuño A, Díez J. NADPH oxidase mediated oxidative stress: genetic studies of the p22(phox) gene in hypertension. Antioxid Redox Signal. 2005;7(9-10):1327-36.

\section{Ready to submit your research? Choose BMC and benefit from:}

- fast, convenient online submission

- thorough peer review by experienced researchers in your field

- rapid publication on acceptance

- support for research data, including large and complex data types

- gold Open Access which fosters wider collaboration and increased citations

- maximum visibility for your research: over $100 \mathrm{M}$ website views per year

At BMC, research is always in progress.

Learn more biomedcentral.com/submissions 